\title{
The Use of Swimmer Bars as Shear Reinforcement in Reinforced Concrete Beam
}

\author{
${ }^{1}$ Moayyad Al-Nasra, ${ }^{2}$ Naem Asha, ${ }^{2}$ Abdelqader Najmi and ${ }^{3}$ Taher Abu-Lebdeh \\ ${ }^{1}$ Department of Engineering Technology, West Virginia University, \\ Institute of Technology, Montgomery, West Virginia 25136, USA \\ ${ }^{2}$ Department of Civil Engineering, University of Jordan, Amman, Jordan \\ ${ }^{3}$ Department of Civil, Architectural and Environmental Engineering, \\ North Carolina A and T State University, NC 27411, Greensboro, United States
}

Received 2012-09-30, Revised 2012-10-13; Accepted 2013-04-30

\begin{abstract}
The behavior of reinforced concrete beams at failure by shear is distinctly different from their behavior by bending, which is considered to be unsafe mode of failure. The shear failure of beams is usually sudden without sufficient advanced warning and the diagonal cracks that develop due to excess shear forces are considerably wider than the flexural cracks. The cost and safety of shear reinforcement in reinforced concrete beams led to the study of other alternatives. Swimmer bar system is a new type of shear reinforcement. It is a small inclined bars, with its both ends bent horizontally for a short distance and welded to both top and bottom flexural steel reinforcement. Regardless of the number of swimmer bars used in each inclined plane, the swimmer bars form plane-crack interceptor system instead of bar-crack interceptor system when stirrups are used. Test results of several reinforced concrete beams will be presented. The effectiveness of the new swimmer bar system as related to the old stirrup system will be discussed. Beam deflection is also targeted experimentally in the lab. Several deflection measurements were taken to study the effect of using new swimmer bar system on deflection. Also the crack width of the tested reinforced concrete beams was monitored.
\end{abstract}

Keywords: Simmer Bar, Deflection, Beam, Crack, Stirrup

\section{INTRODUCTION}

Beams carry loads primarily by internal moments and shears. In the design of a reinforced concrete member, flexure is usually considered first, leading to the size of the section and the arrangement of reinforcement to provide the necessary resistance for moments. Limits are placed on the amounts of flexural reinforcement to ensure ductile type of failure. Beams are then designed for shear. Since shear failure is frequently sudden with little or no advanced warning, the design for shear must ensure that the shear strength for every member in the structure exceeds the flexural strength(Abu-Lebdeh et al., 2011). The shear failure mechanism varies depending upon the cross-sectional dimensions, the geometry, the types of loading and the properties of the member.
Reinforced Concrete (RC) beams are important structural elements that transmit the loads from slabs, to columns. Beams must have an adequate safety margin against bending and shear forces, so that it will perform effectively during its service life. At the ultimate limit state, the combined effects of bending and shear may exceed the resistance capacity of the beam causing tensile cracks. The shear failure is difficult to predict accurately despite extensive experimental research.

Shear failures in beams are caused by the diagonal cracks near the support providing no shear reinforcement. Beams fail immediately upon formation of critical cracks in the high-shear region near the beam supports (Nawy, 2009). Whenever the value of actual shear stress exceeds the permissible shear stress of the concrete used, the shear reinforcement must be provided.

Corresponding Author: Moayyad Al-Nasra, Department of Engineering Technology, West Virginia University, Institute of Technology, Montgomery, West Virginia 25136, USA 
The purpose of shear reinforcement is to prevent failure in shear and to increase beam ductility and subsequently the likelihood of sudden failure will be reduced.

Normally, the inclined shear cracks start at the middle height of the beam near support at approximately $45^{\circ}$ and extend toward the compression zone. Any form of effectively anchored reinforcement that intersects these diagonal cracks will be able to resist the shear force to a certain extent. In practice, shear reinforcement is provided in three forms; stirrups, inclined bent-up bars and combination system of stirrups and bent-up bars.

In building construction, stirrups are most commonly used as shear reinforcement, for their simplicity in fabrication and installation. Normally, spacing between stirrups is reduced to resist high shear stress. Congestion near the support of RC beams due to the presence of the closely spaced stirrups increase the cost and time required for installation.

The use of bent-up bars along with stirrups had been used in the past. In case where all the tensile reinforcement is not needed to resist bending moment, some of the tensile bars where bent-up in the region of high shear to form the inclined legs of shear reinforcement. For example, beams provided with 4 bars of main tensile reinforcement, 2 bars may be bent diagonally in shear region and used as shear reinforcement, while the other 2 bars will be left straight up to the support. The use of bent-up bars is not preferred nowadays. Due to difficulties in construction, bent-up bars are rarely used. In beams with small number of bars provided, the bent-up bar system is not suitable due to insufficient amount of straight bars left to be extended to the support as required by the code of practice.

In this study, several reinforced concrete beams were tested using new shear reinforcement swimmer bar system. Beams with traditional stirrups as shear reinforcement were also tested in order to study the effectiveness of the new swimmer bar system. These beams are used as reference beams. In this investigation, all of the beams are supposed to fail solely in shear, so adequate amount of tension reinforcement were provided to give sufficient bending moment strength. This study aims at investigating a new approach of design of shear reinforcement through the use of swimmer bars provided in the high shear region. The main advantages of this type of shear reinforcement system are: flexibility, simplicity, efficiency and speed of construction.

Piyamahant (2002) showed that the existing reinforced concrete structures should have stirrup reinforcement equal to the minimum requirement specified the code. The theoretical analysis shows that the amount of stirrup of $0.2 \%$ is appropriate. The study concluded that small amount of web reinforcement is sufficient to improve the shear carrying capacity. The study focused on the applicability of the superposition method that used in predicting shear carrying capacity of reinforced concrete beam with a small amount of web reinforcement at the shear span ratio of 3 . Also the failure mechanisms were considered when small amount of stirrup used.

Lesley and Julio (2008) discussed the results of experimental research performed to test the hypothesis that the effective depth does not influence the shear strength of reinforced concrete flexural members that do not contain web reinforcement. The results of eight simply supported reinforced concrete beam tests without shear and skin reinforcement were investigated. The beams were designed such that the effective depth is the variable while the values of other traditionallyconsidered parameters proven to influence the shear strength (such as the compressive strength of concrete, longitudinal reinforcement ratio, shear span-to-depth ratio and maximum aggregate size) were held constant. The values selected for the parameters held constant were chosen in an attempt to minimize the concrete shear strength.

Hamoush et al. (2010) presented several results of experimental investigation on six reinforced concrete beams in which their structural behavior in shear was studied. The research conducted was about the use of additional horizontal and independent bent- up bars to increase the beam resistance against shear forces. The main objectives of that study were studying the effectiveness of adding horizontal bars on shear strength in rectangular beams, the effectiveness of shear reinforcement and determining the optimum amount of both types of shear reinforcement to achieve a shear capacity similar to that of a normal links system. From experimental investigation of the system it was found that, the use of independent horizontal and bentup bars as shear reinforcement were stronger than conventional shear reinforcement system.

\subsection{Swimmer Bars}

A swimmer bar is a small inclined bar, with its both ends bent horizontally for a short distance, welded at the top and the bottom of the longitudinal bars as shown in Fig. 1-3. There are three major standard shapes; single swimmers, rectangular shape and rectangular shape with cross bracings. Several additions to these standard shapes can be explored, such as addition of horizontal stiffener bars in the rectangular shapes, dividing the large rectangle horizontally into smaller rectangles. Additional swimmer bars can also be used. By adding one more swimmer bar to the rectangular shape, the large rectangular shape will be divided vertically into two rectangles. 


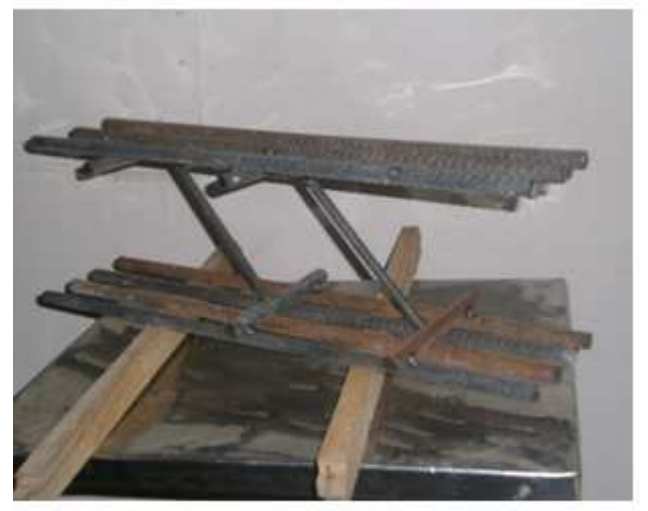

Fig. 1. Single swimmer bar system

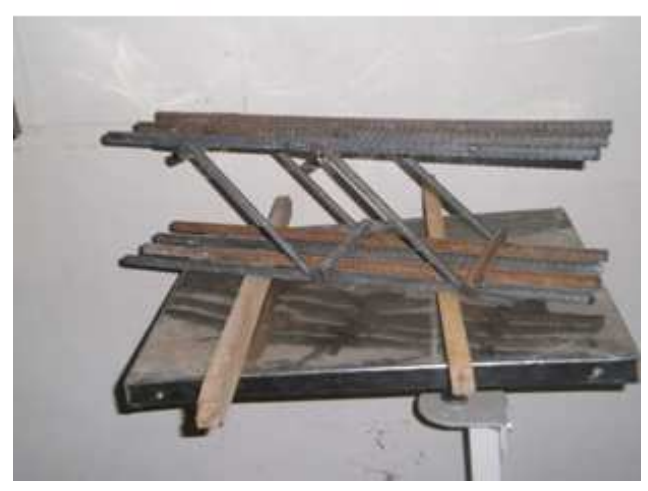

Fig. 2. Rectangular swimmer bar system

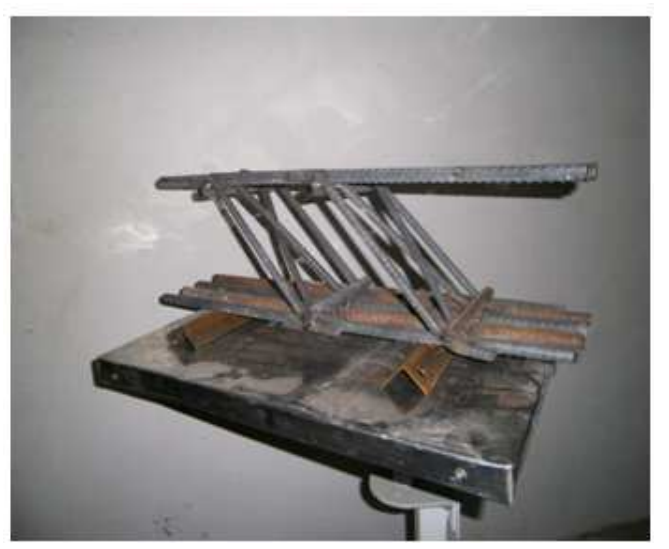

Fig. 3. Rectangular swimmer bar system with cross bracings

Addition of two more swimmer bars will divide the large rectangle vertically into four small rectangles. A combination of horizontal bars and additional swimmer bars may also be explored. This swimmer bar system is integrated fully with the longitudinal steel bars. Several options of the swimmer bar systems are used in order to improve the shear performance of the reinforced concrete beams, reduce the amount of cracks, reduce the width and the length of cracks and reduce overall beam deflection. Different bar diameters can be used in order to add stiffness to the steel cage and increase shear strength of the reinforced concrete beam.

\subsection{ACI Code Provision for Shear Design}

According to the ACI Code, the design of beams for shear is to be based on the following relation Equation 1:

$$
\mathrm{v}_{\mathrm{u}} \leq \phi \mathrm{v}_{\mathrm{n}}
$$

where, $V_{u}$ is the total shear force applied at a given section of the beam due to factored loads and $V_{n}=V_{c}+$ $\mathrm{V}_{\mathrm{s}}$ is the nominal shear strength, equal to the sum of the contribution of the concrete and the web steel if present. Thus for vertical stirrups Equation 2:

$$
\mathrm{v}_{\mathrm{u}} \leq \phi \mathrm{v}_{\mathrm{c}}+\frac{\phi A v J c^{\mathrm{d}}}{\mathrm{s}}
$$

and for inclined bars Equation 3:

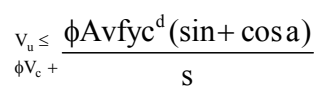

where, $A_{v}$ is the area of one stirrup, $\alpha$ is the angle of the stirrup with the horizontal and $\mathrm{S}$ is the stirrup spacing.

The nominal shear strength contribution of the concrete (including the contributions from aggregate interlock, dowel action of the main reinforcing bars and that of the un-cracked concrete) can be simplified as shown in Equation 4:

$$
\mathrm{V}_{\mathrm{c}}=0.17 \lambda \sqrt{\mathrm{f}_{\mathrm{c}}^{\prime}} \mathrm{b}_{\mathrm{w}} \mathrm{d}
$$

where, $b_{w}$ and $d$ are the section dimensions and for normal weight concrete, $\lambda=1.0$. This simplified formula is permitted by the ACI code expressed in metric units.

\subsection{Suggested Method of Designing Swimmer Bars}

The analysis of needed shear reinforcement using swimmer bar system is based on the truss analogy concept. If $S_{1}$ is the swimmer bar spacing in a single 
truss analogy, $\mathrm{n}$ is the number of bars and As is the area of steel of a single swimmer bar, then Equation 5 and 6:

$$
\mathrm{S}_{1}=\mathrm{nAs}
$$

And:

$$
\frac{T_{s}}{S_{1}}=\frac{T_{s}}{n s}=\frac{V_{s}}{\sin a} \frac{1}{\left(d-d^{\prime}\right)(\cot \beta+\cot \alpha)}
$$

where, $\mathrm{T}_{\mathrm{s}}$ is the tension force in the bent bar, $\mathrm{s}$ is the spacing of the swimmer bars, $\alpha$ is angle between the tension force and the horizontal in the triangular truss and $\beta$ is the angle between the simulated concrete strut and the horizontal in the triangular truss. If there are $n$ swimmers bars within the $s_{1}$ length of the analogous truss chord and if $A_{v}$ is the area of steel of one swimmer bar, then Equation 7:

$$
\mathrm{T}_{\mathrm{s}}=\mathrm{nAvf}_{\mathrm{yt}}
$$

where, $f_{\mathrm{yt}}=$ strength of transverse reinforcement and Equation 8:

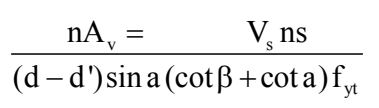

In the case of diagonal tension failure, the compression diagonal makes an angle $\beta=45^{\circ}$ with the horizontal, thus Equation 6 becomes Equation 9:

$$
\mathrm{V}_{\mathrm{s}}=\frac{\operatorname{Avf}_{\mathrm{yt}}\left(\mathrm{d}-\mathrm{d}^{\prime}\right)}{\mathrm{s}}[\sin \mathrm{a}(1+\cot \mathrm{a})]
$$

Which can be simplified as Equation 10:

$$
\mathrm{V}_{\mathrm{s}}=\frac{\operatorname{Avf}_{\mathrm{yt}}\left(\mathrm{d}-\mathrm{d}^{\prime}\right)}{\mathrm{s}}(\sin \alpha+\cot \alpha)
$$

Which is similar to those used by ACI code Equation 11:

$$
\mathrm{V}_{\mathrm{n}}=\mathrm{V}_{\mathrm{s}}+\mathrm{V}_{\mathrm{c}}
$$

\subsection{Tested Beams}

Six reinforced concrete beams were prepared for the test, B1 through B6. All of the same dimension $2000 \mathrm{~mm}$ length, $200 \mathrm{~mm}$ width and $250 \mathrm{~mm}$ depth. The effective length was also kept at constant value of $1800 \mathrm{~mm}$. These beams were designed with $3 ø 14 \mathrm{~mm}$ top steel and $4 ø 16 \mathrm{~mm}$ bottom steel reinforcement. Reference beam
B1 was designed with $10 \varnothing 8 \mathrm{~mm}$ at $600 \mathrm{~mm}$ spacing vertical stirrup at either side. Table 1 shows details of the shear reinforcement of each beam and Fig. 4 shows details of the steel reinforcement for the beam B2. The Beams B3 and B4 is similar but the swimmer bars are of $12 \mathrm{~mm}$ and $10 \mathrm{~mm}$ in diameter respectively. Beam B5 uses cross bracing of $8 \mathrm{~mm}$ in diameter and the swimmer bars are at a larger spacing of $275 \mathrm{~mm}$ compared to the spacing of $137.5 \mathrm{~mm}$ used in the beam B2. The beam B6 does not use any cross bracings and the swimmer bars are spaced at $275 \mathrm{~mm}$ similar to the beam B5.

The compressive strength of concrete is measured according to ASTM C 192-57. Fifteen concrete samples were prepared. The compressive strength of concrete is measured at the 28th day. The concrete compressive strength results range between $34.9 \mathrm{~N} / \mathrm{mm}^{2}$ to $37.2 \mathrm{~N} . \mathrm{mm}^{2}$.

\subsection{Test Procedure}

Prior to testing, the surface of the specimens was painted with white emulsion to make it easy to detect and follow cracks in the concrete beam. At age 28 days, the reinforced concrete beams were prepared for testing. Lines locating the positions of point loads, supports and the middle of each beam were marked. Beams were placed in the testing frame that uses hydraulic jacks. The test was carried out with the specimen placed horizontally in a simple loading arrangement. The beams were supported by solid round steel on their two edges as simply supported member. The effective length of each beam was kept at $1800 \mathrm{~mm}$ measured from the center of each support. All the beams were designed to ensure that the beams will only fail in shear rather than in flexure.

To ensure that shear cracks will occur near the support, two point loads were applied symmetrically to the beam with $\mathrm{a}_{\mathrm{v}}$ less than $2.5 \mathrm{~d}$. In this testing, $\mathrm{a}_{\mathrm{v}} \approx$ $550 \mathrm{~mm}$, where $\mathrm{a}_{\mathrm{v}}$ is shear span (the distance from the point of the applied load to the support) and $d$ is the effective depth of a beam.

A loading jack was placed at the mid-span position above the beam. The load was applied by jacking the beam against the rig base member at a constant rate until the ultimate load capacity of the beam was reached. A universal column section was used to transfer the load to the beam at two point loads via transfer girder. A reasonable time interval was allowed in between 20.0 $\mathrm{kN}$ load increments for measuring deflections, marking cracks, measuring the shear reinforcement strain and recording the ultimate load. Each beam took about $2 \mathrm{~h}$ to complete the test. 


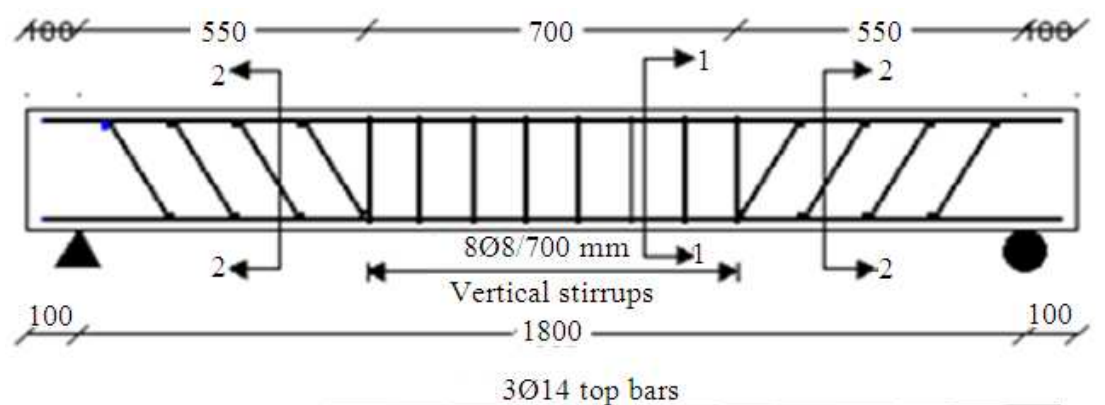

$4 \emptyset 16$ bottom $\mathrm{p}$ bars

Longitudinal sec. in B2 ( $\mathrm{mm})$
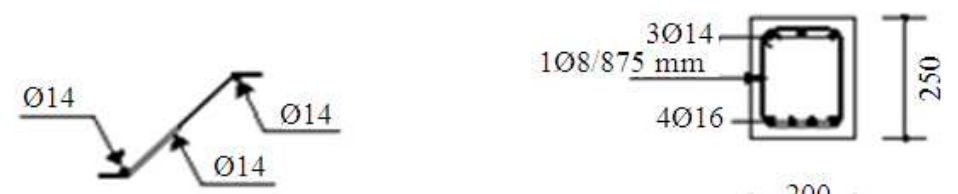

Cross sec (2-2) single swimmer cars $/ 137.5(\mathrm{~mm})$

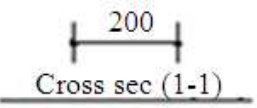

Fig. 4. Details of beam B2

Table 1. Shear reinforcement of beams used in this study

\begin{tabular}{llll} 
& \multicolumn{2}{c}{ Shear reinforcement } & \\
Beam No. & Stirrups & Swimmer bar-system & Total weight of steel cage (N) \\
\hline B1 & $8 \varnothing 8 @ 550 \mathrm{~mm}$ & - & 257.0 \\
B2 & - & Single swimmer $\varnothing 14 @ 137.5 \mathrm{~mm}$ & 263.0 \\
B3 & - & Single swimmer $\varnothing 12 @ 137.5 \mathrm{~mm}$ & 255.0 \\
B4 & - & Single swimmer $ø 10 @ 137.5 \mathrm{~mm}$ & 243.0 \\
B5 & - & Two swimmer with cross $\varnothing 8 @ 275 \mathrm{~mm}$ & 240.0 \\
B6 & - & Two swimmer $\varnothing 8 @ 275 \mathrm{~mm}$ & 230.0 \\
\hline
\end{tabular}

\subsection{Behavior of Beams under Loads}

The first beam designated as B1 is used as a reference beam where traditional stirrups were used as shear reinforcement and no swimmer bars. Loading started at $30 \mathrm{kN}$, where hair cracks appeared in the bottom face between the two applied loads. When loading reached $60 \mathrm{kN}$ hair cracks appeared at the right side of the beam. At the load of $200 \mathrm{kN}$ shear cracks increased in width and length. Finally, shear failure occurred at the load of $260 \mathrm{kN}$.

The beam designated as B2 showed some hair cracks at the load of $140 \mathrm{kN}$. When the load reached $180 \mathrm{kN}$ more hair cracks appeared at the moment region, then by raising the loads up to $220 \mathrm{kN}$ shear cracks appeared at right side of the beam. Finally, shear failure occurred at $310 \mathrm{kN}$ as shown in Fig. 5. Similarly, beams B3, B4, B5 and B6 were studied during the test.

Table 2 shows a summary of the test results. Beams B2 and B3 showed a substantial improvement in the load carrying capacity due to the use of swimmer bar system compared with the traditional stirrup system. With minor change in the amount of steel reinforcement these two beams improved the shear strength by 19.23 and $17.31 \%$ respectively and with respect to the reference beam B1. The beam B4 exhibited a substantial improvement in shear strength performance of approximately $10 \%$ compared to the reference beam B1, but with less total 
steel reinforcement of about $5 \%$ and substantial decrease in shear reinforcement. The load deflection behavior of this beam is similar to the reference beam B1.

The beams B5 and B6 used much less total steel reinforcement compared to the reference beam $\mathrm{B} 1$ of 6.62 and $10.51 \%$ respectively. In these beams $8 \mathrm{~mm}$ diameter swimmer bars were used at large spacing of $275 \mathrm{~mm}$ that reduced the amount of steel shear reinforcement substantially. This kind of shear reinforcement is recommended in case of very congested steel reinforced beams, where shear failure is not of a concern.

\subsection{Beam Deflection}

As can be noticed from Fig. 6 all beams exhibited the same load deflection behavior up the load of $140 \mathrm{kN}$ and deflection of about $4.5 \mathrm{~mm}$, where substantial cracks were observed. At this stage, the beams showed similar stiffness, but beyond this stage, beams started to show different behavior due different shear reinforcement. Beams B2 and B3 showed higher resistance to deflection compared to the reference beam B1, the beam which was reinforced by regular stirrups as shear reinforcement. The swimmer bars used in these two beams added stiffness to the steel cage used. Beam B4 showed similar behavior to the reference beam but at a higher load carrying capacity. Beams B5 and B6 showed less rigidity compared to the reference beam B1 when loaded by twopoint loads due to substantial reduction in steel shear reinforcement used in these two beam.

Table 2. Test result summary

\begin{tabular}{lllcr}
\hline No. & $\begin{array}{l}\text { Ultimate load } \\
(\mathrm{kN}) \text { at failure }\end{array}$ & $\begin{array}{l}\text { Wt of steel } \\
\text { Cage }(\mathrm{N})\end{array}$ & $\begin{array}{l}\text { \%Inc./ Dec. in gage } \\
\text { Wt w.r.t 'B1' }\end{array}$ & $\begin{array}{c}\text { \%Inc./ Dec. in } \\
\text { strength w.r.t 'B1 }\end{array}$ \\
\hline B1 & 260 & 257 & 0.00 & 0.00 \\
B2 & 310 & 263 & 2.33 & 19.23 \\
B3 & 305 & 255 & -0.78 & 17.31 \\
B4 & 285 & 243 & -5.45 & 9.62 \\
B5 & 240 & 240 & -6.62 & -7.69 \\
B6 & 220 & 230 & -10.51 & -15.38 \\
\hline
\end{tabular}

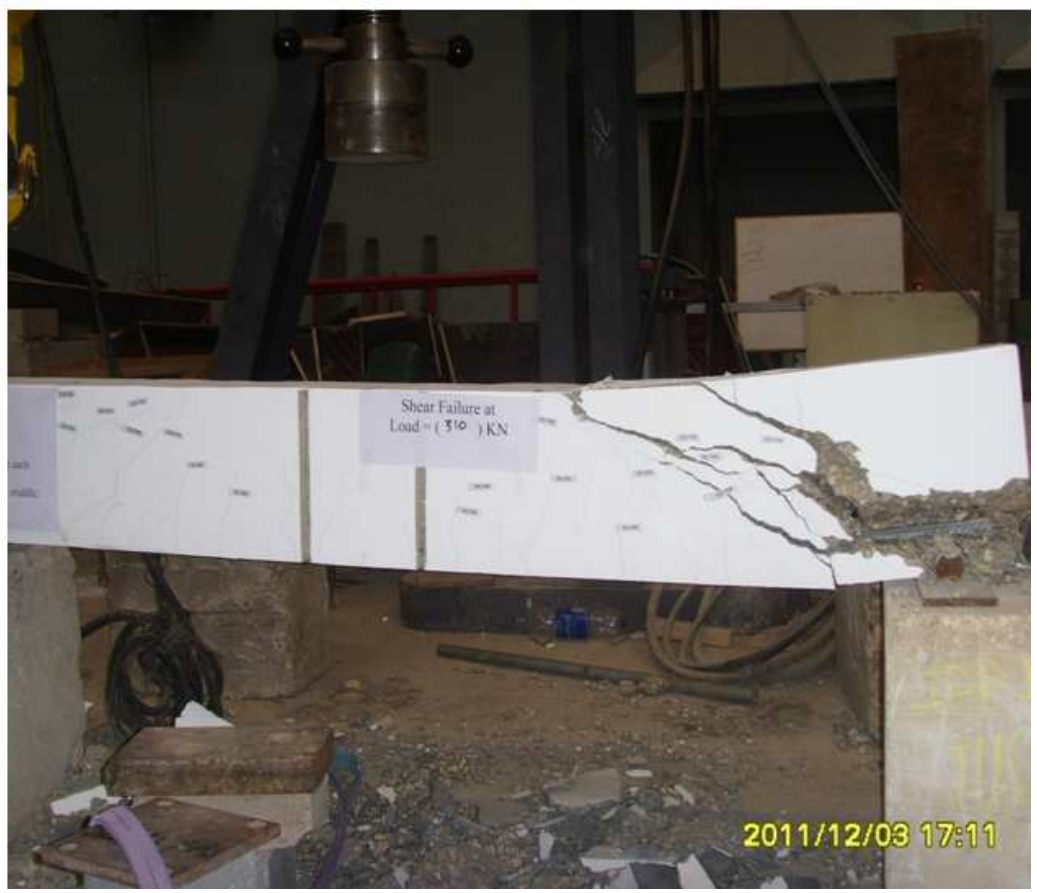

Fig. 5. Beam B2, shear failure at the load of $310 \mathrm{kN}$ 


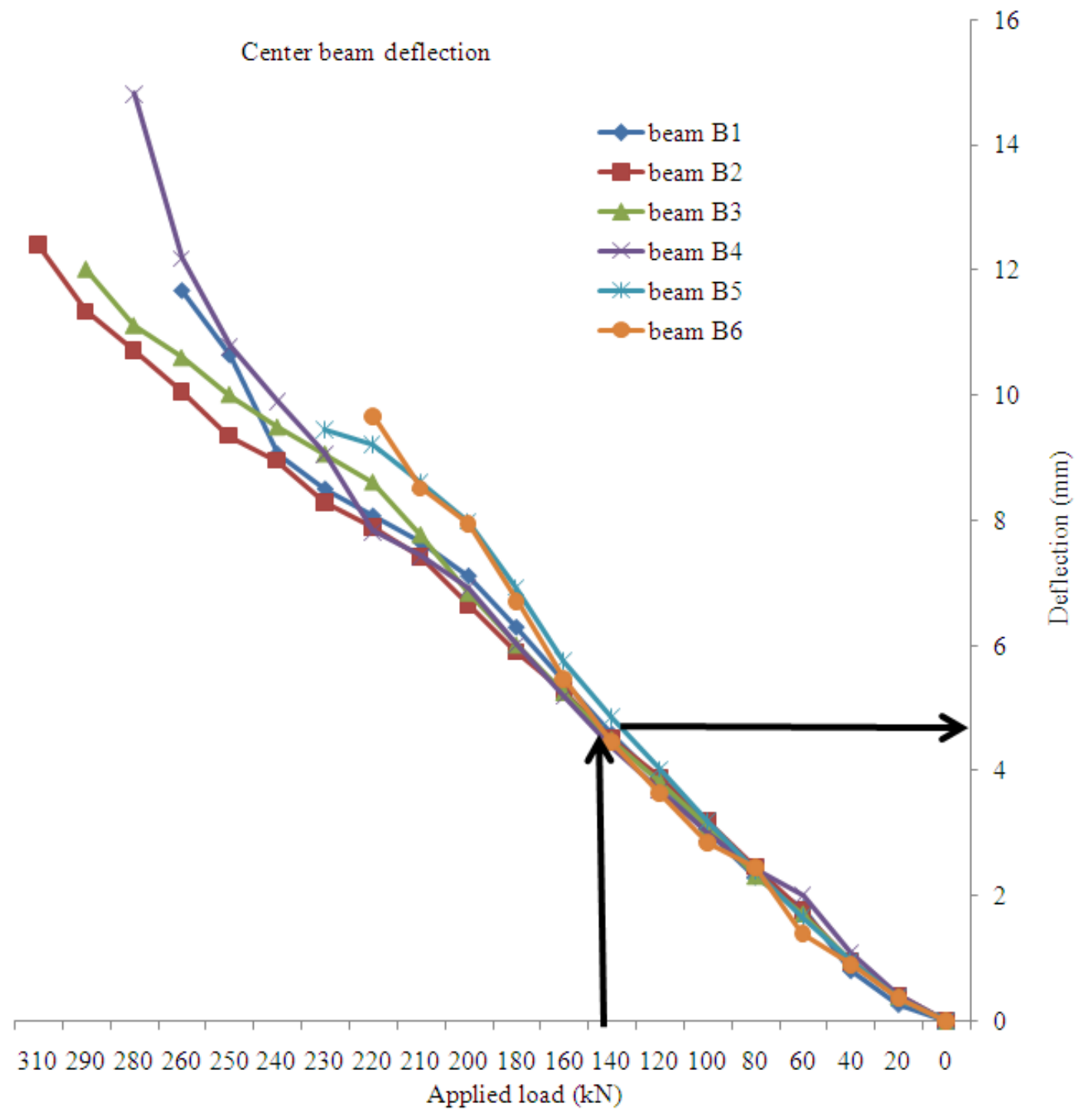

Fig. 6. Central measured beam deflection of all tested beams, B1-B6

\section{CONCLUSION}

Experimental test results showed substantial improvement in the shear performance of the reinforced concrete beams by using the new swimmer bars system in comparison with the traditional stirrup system. The beam deflection is also reduced along with the number and width of cracks in the tested beams under progressive applied loads. The new swimmer bar system can be at a great advantage over the traditional stirrup system when used in congested reinforced concrete beams.

\section{REFERENCES}

Abu-Lebdeh, T., S. Hamoush, W. Coi and M. Al Nasra, 2011. High rate-dependent interaction diagrams for reinforced concrete columns. Am. J. Eng. Applied Sci., 4: 1-9. DOI: 10.3844/ajeassp.2011.1.9

Hamoush, S.A., T. Abu-Lebdeh and T. Cummins, 2010. Deflection behavior of concrete beams reinforced with PVA micro-fibers. Const. Build. Mater., 24: 2285-2293.

DOI:

10.1016/j.conbuildmat.2010.04.027 
Lesley, H.S. and A. Julio, 2008. Effect of depth on the shear strength of concrete beams without shear reinforcement. USA Portland and Cement Association.

Nawy, E.G., 2009. Reinforced Concrete: A Fundamental Approach. 6th Edn., Prentice Hall, Upper Saddle River, N.J., ISBN-10: 0135029325, pp: 933.
Piyamahant, S., 2002. Shear behavior of reinforced concrete beams with a small amount of web reinforcement. Kochi University of Technology. 